\title{
Questões ambientais e políticas de saúde pública no Brasil
}

Os processos industriais que marcaram a evolução do capitalismo desde meados do século XVIII, definiram modelos de índole energéticoambiental e configuraram padrões energotécnicos que tiveram seus impactos sobre as populações a nível das migrações, êxodo rural e nível de vida. Desse modo, a Primeira Revolução Industrial (PRI), ocorrida na Inglaterra nos séculos XVIII e XIX, suas implicações e desdobramentos de ordem institucional e econômica, promoveram um grande deslocamento das populações dos campos para as cidades. Desmontaram-se relações, formas de organização produtiva, econômica e social, despejando-se enorme quantidade de camponeses despossuídos nas cidades. Nestas, o aparelho produtivo-industrial mostrava-se incipiente para promover a absorção desses imensos contingentes migratórios. Os grandes conglomerados industriais afetos à Segunda Revolução Industrial (SRI) também utilizaram mão-de-obra migrada dos campos, mas a realidade que desponta com a Terceira Revolução Industrial (TRI) abre espaço para a agroenergia, alcoolquímica e uma nova agro-indústria enquanto motores de modernização, absorção de mão-de-obra e atenuantes do êxodo rural.

Palavras-chave: Indústria; Energia; Meio Ambiente; Agroenergia; Fixação no Campo.

\section{Environmental and public health policy issues in Brazil}

\begin{abstract}
The industrials processes that marked the evolution of capitalism since the mid-eighteenth century, defined models of energy-environmental nature and configured energetic and technical patterns that have had their impacts on populations at the level of migration, rural exodus and standard of living. Thus, the First Industrial Revolution (FIR), which took place in England in the eighteenth and nineteenth centuries, its implications and consequences of institutional and economic order, promoted a large displacement of people from the countryside to the cities. Dismounted up relationships forms of productive, economic and social organization, and pouring up huge amount of dispossessed peasants in cities. Indeed, mechanized industrial production showing up incipient to promote the absorption of these huge migratory contingents. Large industrial conglomerates pertaining to the Second Industrial Revolution (SIR) also used hand labor migrated from the fields, but the reality that dawns with the Third Industrial Revolution (TIR) makes room for agro-energy, alcohol chemistry and a new agroindustry while modernization of engines, hand labor absorption and mitigating the rural exodus.

Keywords: Industry; Energy; Environment; Agro-energy; Fixing the field.
\end{abstract}

\section{Topic: Epidemiologia e Saúde Ambiental}

Reviewed anonymously in the process of blind peer.
Received: 14/03/2016

Approved: 04/08/2016
Manoel Gonçalves Rodrigues

Universidade Estadual de Campinas, Brasil

http://lattes.cnpq.br/5940113046592928

manoel.rodrigues@terra.com.br

Fernando José Pereira da Costa

Universidade de Santiago de Compostela, Espanha

http://lattes.cnpq.br/0908286687921354

fjpcosta@sapo.pt

\section{Referencing this:}

RODRUGUES, M. G.; COSTA, F. J. P.. Questões ambientais e políticas de saúde pública no Brasil. Revista Ibero-Americana de Ciências Ambientais, v.7, n.3, p.72-81, 2016. DOI: http://doi.org/10.6008/SPC2179-6858.2016.003.0006 


\section{INTRODUÇÃO}

A evolução do capitalismo a partir de meados do século XVIII implica na entrada e consolidação do mesmo na etapa industrial. Começando com a Primeira Revolução Industrial (PRI), que ocorreu na Inglaterra de finais do século XVIII a meados do século XIX, o deslocamento de enormes contingentes populacionais dos campos para as cidades, fruto de transformações de ordem técnica, econômica e institucional, com impactos a nível dos direitos de propriedade e da própria concentração fundiária, constituiria o proletariado industrial urbano e um vasto exército industrial de reserva, uma vez que o aparato produtivo-industrial (ainda incipiente) mostrava-se tecnicamente incapaz de absorver esses imensos contingentes de migrantes excluídos/expoliados de todo e qualquer direito. Com isso, desvalorizam-se os salários e as remunerações do vasto contingente de camponeses (sub)proletarizados.

A Segunda Revolução Industrial (SRI), que se verificaria entre finais do século XIX e o início dos anos 70 do século $X X$, também se valeria do êxodo rural e da mão-de-obra possibilitada por este último, a constituir o imenso contingente de trabalhadores afeto às unidades industriais de grande porte típicas do segundo processo industrial-revolucionário. O taylorismo-fordismo, a produção em massa e as melhorias salariais conduziriam à expansão do consumo e à absorção dos contingentes populacionais e o período posterior à Segunda Guerra Mundial assistiria ao crescimento populacional. No âmbito dos países em desenvolvimento, mormente nos de industrialização recente, incrementa-se a pressão demográfica e o êxodo rural.

A Terceira Revolução Industrial (TRI) ocorre num contexto de contenção e retrocesso demográfico, mormente no âmbito dos países orgânico-centrais, com o processo de desindustrialização fornecendo o mote para argumentos propícios à constituição de uma sociedade pós-industrial, também dita da informação. As mudanças culturais e sociais dos anos 60 do século $\mathrm{XX}$, e o desejo pela manutenção dos elevados níveis de vida, forneceriam a base para o refreamento demográfico, mormente no mundo orgânicocentral. Mesmo no âmbito do mundo em desenvolvimento ganharia espaço a narrativa da contenção demográfica, muitas vezes conduzindo a práticas de índole coercitiva.

\section{DISCUSSÃO TEÓRICA}

\section{O Caso Brasileiro}

A transição demográfica brasileira apresentaria características bastante específicas, uma vez que se tem o rejuvenescimento da fecundidade e o adiamento da reprodução para depois dos 30 anos. São estes os principais aspetos a marcar a evolução demográfica do país. De fato, observa-se a significativa queda da fecundidade, o envelhecimento da população e carência futura de mão-de-obra jovem. Assim, o Brasil passaria a apresentar certas características demográficas típicas dos países orgânico-centrais, embora fazendo parte da categoria em desenvolvimento. Contudo, a realidade demográfica brasileira mostra, como elemento inovador e enquanto fator que não se verifica a nível dos países orgânico-centrais, o rejuvenescimento da fecundidade. 
Na realidade, se no início da década de 1980 o pico da fecundidade encontrava-se entre os 25 aos 29 anos, em meados da passada década passa a se concentrar na faixa dos 20 aos 24 anos de idade. Isto implicaria um peso cada vez maior da população idosa face ao seu contingente, com reflexos sobre o redirecionamento dos gastos públicos, uma vez que poderia haver chance de melhorar a cobertura/qualidade de ensino e também de se reduzir a pressão sobre o universo de recursos naturais e o meio ambiente, muito embora com grandes chances de ocorrer uma forte crise no mercado de trabalho e um desacelerar do processo de crescimento econômico, caso não se aproveite essa dinâmica demográfica específica (HAAG et al., 2012).

No caso do Brasil, a população total do país multiplicar-se-ia por 5 entre 1800 e 1900 e por 10 de 1900 a 2000, o que significa que em cerca de dois séculos a população a viver no território brasileiro teria aumentado 50 vezes. De fato, tal representaria um dos maiores crescimentos demográficos do mundo. No entanto, a densidade demográfica brasileira pouco ultrapassaria os 20 habitantes por quilômetro quadrado (23 habitantes/km2), em 2010, uma vez que se partiria de uma base reduzida. É uma densidade maior do que a da Austrália (3 habitantes/km2), Canadá (3 habitantes/km2) e da Rússia (8 habitantes/km2), mas muito menor do que a densidade da China (140 habitantes/km2) e da Índia (373 habitantes/km2). Contudo, esse desempenho populacional não se irá repetir no século XXI, uma vez que as estimativas nacionais e internacionais para 2030 apontam para um pico populacional a variar entre 210 a 224 milhões de habitantes, para em seguida iniciar-se o declínio. Para tal, a mortalidade infantil continuará a cair, a esperança de vida a subir, não se verificando grandes saldos migratórios, mas com pouca certeza quanto à fecundidade. De fato, considerando-se o ano de 2010, a taxa de fecundidade total do Brasil ficava-se por 1,9 filhos/mulher, abaixo do nível de reposição (2,1 filhos/mulher), com estimativas a apontar para algo entre 1,7 filhos/mulher (20452050) e 2 filhos/mulher (2100) (ALVES, 2012).

Dessa maneira, para 2050, as projeções apontariam que a população brasileira poderia chegar a 259 milhões (hipótese alta), 223 milhões (hipótese média) e 191 milhões (hipótese baixa). Já para 2100, os resultados se quedariam, respetivamente, em 314, 177 e 93 milhões de habitantes. Em outras palavras, o país poderia chegar a 2100 com uma população a variar 3,4 vezes entre a hipótese baixa e a alta. Contudo, o mais provável é chegar-se a 2100 com um total em torno dos 170 milhões de habitantes, o que indicaria um crescimento zero no século XXI. Isto ocorreria em razão do movimento evolutivo de acelerado recuo mostrado pela fecundidade, a partir do momento em que os filhos deixam de ser possíveis fatores de benefício/rendimento e passam a ser elementos de custo (saúde, educaçãoe alimentação), em razão do acelerado (e desordenado) processo de urbanização, industrialização e secularização vivido pelo país. Com efeito, faz meio século que se observa o declínio das taxas de fecundidade no Brasil, perfilando-se o país como detentor de uma significativa população de idosos, com as pessoas com 60 ou mais anos de idade a representar $12 \%$ da população total, percentual que deve chegar a quase 30\% em 2050 (ALVES, 2012). 


\section{Demografia, Meio Ambiente e Saúde}

De forma efetiva, existe um vasto conjunto de relações interativas entre os seres humanos e o meio ambiente, de modo a condicionar a ação dos primeiros sobre os segundos. Tal implica na necessidade de preservação da natureza e do universo de recursos naturais que constituem o meio no qual os seres humanos vivem, trabalham, produzem e dele obtêm o seu sustento. Logo, o aumento da população, a demanda crescente por bens de consumo, matérias-primas e insumos acabam por impactar pesadamente o meio ambiente e todo o ecossistema planetário. Assim sendo, todo esse universo inter-relacional implica na ideia (e necessidade fulcral) de preservação.

$\mathrm{Na}$ verdade, a questão do meio ambiente passa pelo gerenciamento demográfico, uma vez que o crescimento populacional tem impacto sobre o universo existente de recursos naturais e o próprio equilíbrio ecossistêmico. Desse modo, seria possível ultrapassar o fatalismo malthusiano através do recurso a uma base tecnológico-produtiva e técnico-organizacional racionalizadora e redutora de perdas/desperdícios, que possibilitasse a adoção/implementação de um modo de produção sustentável, de forma a incorporar a mirada demográfica à análise/reflexão meio ambiental (SOUZA et al., 2012).

Ao se privilegiar o relacionamento sistêmico-interativo "Demografia-Meio Ambiente», abrem-se amplas perspectivas face à real compreensão do impacto da ação humana sobre o meio (e, de forma mais alargada, com relação ao planeta como um todo), bem como quanto à complexidade que caracteriza o preservar da saúde humana. Assim sendo, a componente meio ambiental deve interagir com as questões afetas à saúde numa perspectiva conservacionista/sustentável, o que obriga a uma interação dinâmicosistêmica e sinérgico-interativa com a questão da preservação e grande parcimônia a nível da exploração do universo existente de recursos naturais.

Por outro lado, inúmeros e muitos são os problemas a afetar a população mundial e o desenvolvimento, com a questão demográfica relacionando-se diretamente à questão meio ambiental, guiando-se pelo binômio «População-Sustentabilidade». De fato, a discussão sobre a questão populacional relaciona-se à situação de miséria que caracteriza a maior parte das populações dos países em desenvolvimento, e à relativa ineficácia de muitas das políticas públicas. Embora esses aspetos não se devam única e exclusivamente ao crescimento da população, este não pode ser ignorado ao se analisar a problemática do desenvolvimento, a questão do baixo nível de vida das populações e os impactos sobre a degradação meio ambiental (FONTANA et al., 2015).

É extremamente necessário que o trinômio dinâmico-interativo «Demografia-Meio AmbienteSaúde», marcasse todas as iniciativas de índole político-institucional direcionadas à promoção do crescimento econômico e do desenvolvimento social. Dessa maneira, o gerenciamento demográfico deveria ser considerado no contexto da configuração/implementação das políticas públicas direcionadas à promoção do desenvolvimento (econômico, social e humano), de modo a assegurar que o crescimento ocorra de forma coerente com a preservação do meio ambiente, indo ao encontro da promoção/preservação da saúde humana. 
Com efeito, inúmeras são as variáveis implicadas no processo de crescimento da população, constituindo-se em algo de particular dificuldade a delimitação de uma dimensão ótima de população, quer a nível dos estudiosos, pesquisadores e especialistas que se vêm debruçando sobre a questão, quer em termos dos organismos internacionais e multilaterais especializados, quer ainda quanto às nações, formuladores de políticas e governantes. De fato, inúmeras são as variáveis e fatores a atuar sobre o fenômeno populacional, indo do nível de desenvolvimento da área, território ou país, passando pelo grau de instrução e nível de educação, até pela qualidade do sistema público de saúde à disposição das populações.

Na realidade, o que ocorre no Brasil e no mundo é que a população continua a crescer mesmo depois que as pessoas passam a ter um menor número de filhos, o que caracteriza o conceito de inércia demográfica. Com a taxa de fecundidade a nível da reprodução, a população não crescerá nem diminuirá, permanecendo estável no longo prazo. Com a fecundidade acima do efeito de inércia demográfica, a população crescerá no longo prazo. Por outro lado, com a fecundidade abaixo do efeito de inércia, a população irá diminuir no longo prazo. O conceito de inércia demográfica equivale a 2,1 filhos/mulher. Esse conceito utilizado pela demografia alerta para o fato de que a população brasileira continuará a crescer até o quinquênio 20352040, começando a cair a partir do final do mesmo.

A população brasileira continuará a crescer em virtude da estrutura etária jovem do país. De fato, muito embora as mulheres já estejam a ter menos filhos do que o necessário para a reposição, existem muitas mulheres em período reprodutivo e um percentual pequeno de pessoas com idades mais avançadas. Entretanto, praticamente todos os países orgânico-centrais apresentam fecundidade abaixo do nível de reposição e muitos deles já apresentam declínio populacional. No mais, ainda que ocorra a diminuição dos casos de gravidez indesejada e se verifique a universalização do acesso à saúde reprodutiva, o crescimento populacional a nível mundial far-se-á acompanhar por um crescimento ainda maior da economia, em especial nas nações em desenvolvimento (ALVES, 2010).

De fato, chegando-se a 2050 com a população mundial passível de se aproximar dos 9 bilhões de habitantes e com o crescimento do PIB a 3,5\% ao ano (quadruplicação em quatro décadas), os impactos sobre o meio ambiente seriam enormes. Na verdade, sendo inevitável o crescimento, caberia reduzir o impacto das atividades antropogênicas sobre o meio ambiente. Essas medidas iriam desde à maior presença das fontes renováveis de energia até à promoção de esforços direcionados à reciclagem (mormente de materiais), reutilização e reaproveitamento do lixo, à utilização do lodo residual dos esgotos para a produção de fertilizantes e gás metano, passando também pelo estímulo à conservação/racionalização de energia, pela priorização do transporte coletivo, pelo recurso crescente à ferroviarização (mormente no transporte de cargas) e à metroviarização (nas áreas urbanas/metropolitanas), na utilização de energias renováveis nos meios de transporte (etanol/álcool etílico e biodiesel), até chegarem à entrada crescente da biomassa a nível da base energético-produtiva, à introdução crescente de inovações quanto aos consumos energéticos intermédios e finais, ao acelerar do desenvolvimento tecnológico para a viabilização de novas trajetórias energo-ambientais e, por arrastamento, à produção de toda uma gama de equipamentos e engenhos (ALVES, 2010). 
A nível mundial, a taxa de fecundidade caiu entre 1950 (5,0 filhos/mulher) e 2010 (2,5 filhos/mulher), num recuo de $50 \%$. Contudo, o número de nascimentos, em idêntico período, cresceria cerca de $40 \%$. De algo em torno de pouco abaixo de 100 milhões de crianças, subiu para algo ao redor de 140 milhões de crianças. Isto ocorreu em razão do aumento no número de mulheres que se situam no denominado período reprodutivo (de 15 a 49 anos de idade), o que faria com que o volume de nascimentos aumentasse ainda que com a diminuição do número médio de filhos por mulher. As projeções indicariam que a se manter a taxa de fecundidade registrada em 2010 (a nível da reposição), o número de nascimentos por ano, a nível mundial, manter-se-ia relativamente estável (ao redor das 140 milhões de crianças). De fato, se a esperança de vida em termos mundiais alcançar os 80 anos de idade, a população do planeta, em finais do século XXI, pode vir a se estabilizar em 11,2 bilhões de habitantes (140 milhões multiplicado por 80 ). No entanto, o crescimento da população implica num maior impacto da ação antrópica sobre o meio ambiente, principalmente a nível da exploração dos recursos naturais. Na relação entre óbitos e nascimentos, é muito difícil bater o crescimento demográfico a curto prazo, em razão da inércia demográfica e à estrutura etária da população mundial, que é relativamente jovem (ALVES, 2014).

Contudo, fica difícil a obtenção de um decréscimo populacional com o recuo que se verifica nas taxas de mortalidade, o que remeteria a questão para a redução da taxa de fertilidade global (para algo em torno de 1,8 filhos/mulher). Com isso, se assistiria ao declínio contínuo da quantidade de nascimentos, que se mostraria passível de aliviar a pressão demográfica sobre o meio ambiente. De fato, haveria muito a fazer para reduzir o ritmo de crescimento demográfico, do acesso a meios de regulação da fecundidade à diminuição do elevado número de casos de gravidez indesejada, chegando à universalização dos serviços de saúde sexual e reprodutiva. Isto passaria por iniciativas no âmbito das políticas públicas, que não se deveriam limitar aos controles de natalidade, mas também à informação e à conscientização da população em idade de procriação. Assim sendo, as políticas públicas de saúde não se limitariam a ações de curto prazo, mas também a iniciativas de médio/longo prazo, nas quais os objetivos contracionistas com relação às expectativas de crescimento vegetativo da população, seriam complementadas por uma visão conservacionista face ao impacto sobre a base de recursos naturais do planeta e o assegurar de maiores níveis de sustentabilidade face ao modelo de desenvolvimento

\section{Ambiente Multidisciplinar}

O debate científico em torno da questão do meio ambiente e, mais especificamente, da relação «Meio Ambiente-Saúde», vem sendo marcado pela tradicional divisão entre os enfoques oriundos das ciências naturais e da tecnologia, de um lado, e das ciências sociais e humanas, de outro, deixando-se influenciar por vários tipos de reducionismo (naturalista/biologista e tecnológico/tecnocrático, por exemplo). Com isso, o complexo sistema "Saúde-Doença» implica na consideração de inúmeros condicionantes externos, por meio de concessões abrangentes do social como determinante central do mesmo, aí incorporando-se a questão meio ambiental e definindo-se a conexão "Meio Ambiente-Saúde- 
Desenvolvimento», para assim configurar-se a discussão em torno do conceito de Desenvolvimento Sustentável.

Na realidade, em termos históricos, as ações/intervenções humanas sobre o meio, caracterizaramse por aspetos prejudiciais (a nível potencial ou efetivo) às condições de vida/saúde das atuais e futuras gerações. Efetivamente, o conceito de desenvolvimento ou modelo de desenvolvimento surge como elemento de sintetização das ações de cunho antropogênico, de maneira a superpor dinâmicas de diferentes naturezas e a abranger o meio ambiente físico-biológico, a produção, a tecnologia, a organização social, a economia, a cultura, etc. (PORTO, 1998).

Logo, será a análise dos mecanismos e processos afetos aos próprios modelos de desenvolvimento (a saber: poluição química, falta de saneamento, doenças respiratórias da população infantil, mortes por violência, mecanismos de participação e controle, etc.) que se constituirá em elemento crítico dos aspetos nocivos dos mesmos e em contrapontos à formulação de um modelo alternativo de desenvolvimento, qual seja: o Desenvolvimento Sustentável. Tal exige novos conceitos e metodologias para a formulação de políticas públicas que passem a considerar o meio ambiente e os impactos ambientais antropomórficos de forma multidisciplinar/interdisciplinar, global e inovadora. Isto poderá conduzir à configuração de novas formas de ação/intervenção (convergentes) do homem sobre o meio ambiente (políticas públicas inovadoras, novos modelos de produção, novos parâmetros tecnológicos, mudanças culturais nos padrões de comportamento/consumo, remediação de áreas contaminadas, tratamento de pessoas afetadas, etc.). Os aspetos nocivos e muitas vezes perversos da ação e intervenção antropogênica, quando estudados, analisados e devidamente avaliados, podem vir a se constituir em importantes subsídios e até mesmo em elementos configuradores de novos modelos a privilegiar o binômio «Desenvolvimento-Meio Ambiente» (PORTO, 1998).

A partir da descentralização, vista como estratégia de mudança nas relações "Estado-Sociedade», teve a gestão das iniciativas de cunho social, particularmente na área da saúde, enquanto suporte de sustentação, a descentralização/intersetorialidade, principalmente no município enquanto espaço definido em termos territoriais/sociais e num contexto de integração interinstitucional e ação intersetorial. 0 movimento de descentralização nas áreas das políticas sociais, notadamente no campo da saúde, buscava ganhos em termos de agilidade e eficiência. De fato, a partir da descentralização, vista como estratégia de mudança nas relações «Estado-Sociedade», teve a gestão das iniciativas de cunho social, particularmente na área da saúde, enquanto suporte de sustentação, a descentralização/intersetorialidade, principalmente no município enquanto espaço definido em termos territoriais/sociais e num contexto de integração interinstitucional e ação intersetorial.

O movimento de descentralização nas áreas das políticas sociais, notadamente no campo da saúde, buscava ganhos em termos de agilidade eficiência. De fato, a descentralização dos serviços de saúde, mormente no caso de um país de dimensões continentais como o Brasil, poderia representar uma maior e mais rápida apreensão dos problemas, assim como a definição das prioridades, como ainda o atendimento mais expedito das demandas das populações (JUNQUEIRA, 1997 citado por DRAIBE, 1993). 
Já a lógica intersetorial de atuação deve referir-se basicamente à população e ao espaço por ela ocupado, de modo a identificar as questões problemáticas e as possíveis soluções para as mesmas. Assim, a base populacional e geográfica permite que se identifiquem os problemas e as possibilidades quanto à sua solução, tendo como fito melhorar a qualidade de vida. Com a intersetorialidade, articulam-se saberes/experiências afetos à área do planejamento, de modo a servir de base à implementação de políticas públicas direta e/ou indiretamente afetas à esfera da saúde. Assim sendo, a saúde passa a ser vista de forma sistêmica com relação a outros segmentos das políticas públicas, consolidando-se uma forma de ação lastreada nos esquemas relacionais (e interrelacionais) homem/natureza, homem/homem, natureza/saúde e homem/saúde, a terem como suporte teórico-conceitual e base da ação político-público-administrativa o binômio sistêmico-interativo «Meio Ambiente-Saúde».

Neste sentido, caberia registrar que pelo conceito de intersetorialidade, a questão da saúde passa a ser vista como algo a transcender a esfera sócio-política, incorporando a racionalidade meio ambiental e tendo em conta o enquadramento das relações a compor a interação dinâmico-sinérgica «Meio AmbienteSociedade» e definindo um novo delineamento quanto à questão do desenvolvimento (JUNQUEIRA, 1997; JUNQUEIRA et al., 1997; PRATS, 1973; RONDINELLI, 1981).

Por outro lado, o relacionamento «Demografia-Meio Ambiente» na formulação e implementação das políticas públicas implica em considerar a finitude do universo de recursos naturais e o impacto que o crescimento populacional possa ter sobre os níveis de consumo de bens e serviços, de modo a sobrecarregar a base desses mesmos recursos e a impactar adversamente o meio ambiente. Entretanto, a questão passa também pelos hábitos de consumo e pela extratificação social dos mesmos, uma vez que não basta apontar o consumismo perdulário em razão dos excedentes populacionais, mas também considerar que o mesmo se concentra nas mãos de segmentos privilegiados da sociedade a nível da distribuição/apropriação dos rendimentos. Isto é pacífico no caso dos países periféricos/semiperiféricos (com grande notoriedade no que se refere ao Brasil), cujo modelo socioeconômico de crescimento talvez seja bem mais preocupante do que a dinâmica evolutiva do processo demográfico relativamente à degradação ambiental.

O trinômio «Demografia-Meio Ambiente-Saúde», passaria não apenas pelo simples controle da natalidade, mas antes pela implementação de políticas públicas direcionadas à promoção efetiva da saúde no sentido amplo (notadamente para os segmentos menos favorecidos da população), à coleta eficiente e ao adequado tratamento dos lixos urbanos, à intervenção urbanística em áreas de risco, à conversão das favelas em bairros (integrados e não segregados a nível da malha urbana/metropolitana) e à promoção da integração profissional, educacional e social das áreas/populações marginalizadas.

O atendimento das demandas sociais tendo como base a interação "Meio Ambiente-DemografiaSaúde«, passa pela intersetorialidade das políticas públicas, de modo a se alcançar níveis elevados de eficácia e eficiência, quer a nível das políticas setoriais, quer no âmbito de iniciativas de índole global. Com isto, a intersetorialidade passaria a ser um elemento fundamental na efetiva articulação entre as políticas governamentais, as instituições que as formulam/implementam e a sociedade civil, a ter como resultado a 
obtenção de ganhos efetivos para a população, de modo a ultrapassar a fragmentação das iniciativas políticas emanadas da esfera público-administrativa.

Assim sendo, a intersetorialidade tende a superar os conflitos de interesses diversos no contexto da formulação e implementação das políticas públicas. Efetivamente, a intersetorialidade superaria as limitações afetas ao enfoque setorial e não integrado que caracteriza as políticas públicas nas sociedades em desenvolvimento, nas quais se inclui o caso brasileiro (NASCIMENTO, 2010).

Na verdade, os riscos da perda da capacidade do Estado para definir minimamente critérios a nível do meio ambiente e saúde, no contexto das políticas econômicas, científico-tecnológicas e produtivoindustriais, tem como consequência imediata o repasse total à iniciativa privada de competências de caráter regulatório como por exemplo as auditorias ambientais. Tal representaria a parcela meio ambiental do movimento mais amplo em termos de acúmulos crescentes de desigualdades, de modo a poder aumentar ainda mais os níveis de exclusão social e o grau de degradação das condições ambientais.

\section{CONSIDERAÇÕES FINAIS}

As questões afetas à saúde, em particular à saúde pública, devem na mesma interagir, de modo sistêmico, com todos esses aspetos e componentes, assim como com a esfera político-públicogovernamental, no sentido de serem concebidas, delineadas e aplicadas políticas públicas efetivamente integradas. De fato, não bastam apenas as iniciativas direcionadas à saúde, antes inserindo-as num complexo integrado de ações direcionadas às diversas componentes do contexto nacional.

No caso do Brasil, ao se buscar analisar os relacionamentos interativos "Meio AmbienteDemografia», «Meio Ambiente-Saúde» e «Meio Ambiente-Desenvolvimento», há que se referir à questão do êxodo rural, caraterizado pela expulsão dos pequenos proprietários rurais ou de camponeses sem terra do campo, em razão da concentração fundiária e/ou da falta de condições para o prosseguimento das atividades relacionadas à pequena lavoura, à pecuária de reduzido porte e à agricultura familiar ou mesmo de subsistência.

Para além das condições climatéricas desfavoráveis, da carência de água para a irrigação das pequenas plantações, da falta de infraestruturas para o escoamento da produção, do não apoio mínimo à atividade do pequeno produtor rural, a pequena propriedade agropecuária de cunho familiar sofre pressões a nível da especialização e ultra-especialização da sua produção, da dependência dos canais de distribuição de grande porte e do atrelamento a estruturas produtivas e mercantis afetas a grandes grupos econômicos nacionais e transnacionais, a contar com elevados níveis de concentração de capital, sofisticada capacidade gerencial, alto grau de incorporação de tecnologia, e na maior parte das vezes oriunda de empresas transnacionais ou mesmo importada, se verticalmente e mesmo horizontalmente integrados.

\section{REFERÊNCIAS}


ALVES, J. E. D.. Redução da fecundidade e qualidade de vida humana e ambiental. 2014.

BAUER, G.; ROUX, J-M.. La rurbanisation ou la ville éparpillée. Paris: Edition Du Seuil, 1976.

CARDOSO, M. M.; FRITSCHY, B. A.. Revisión de la definición de espácio rururbano y sus criterios de delimitación. Contribuciones Científicas G/EA, n.24, p.27-39, 2012.

DRAIBE, S. M.. As Políticas sociais e o neoliberalismo: reflexões suscitadas pelas experiências latino-americanas. Revista USP, v.17, p.86-101, 1993.

FONTANA, R. L. M.; SANTANA, S.; SILVA, J. A. B.; RODRIGUES, A. J.. Teorias demográficas e o crescimento populacional no mundo. Ciências Humanas e Sociais Unit, v.2, n.3, p.113-124, 2015.

HAAG, C.; SCARPELLI, V.. Brasil em transição demográfica. Pesquisa FAPESP, n.192, p.76-81, 2012.

JUNQUEIRA, L. A. P.. Novas formas de gestão na saúde: descentralização e intersetorialidade. Saúde e Sociedade, v.6, n.2, p.31-46, 1997

JUNQUEIRA, L. A. P.; INOJOSA, R. M.. Desenvolvimento social e intersetorialidade: a cidade solidária. São Paulo: FUNDAP, 1997.

NASCIMENTO, S.. Reflexões sobre a intersetorialidade entre as políticas públicas. Serviço Social e Sociedade, n.101, p.95120, 2010.
PORTO, M. F. S.. Saúde, ambiente e desenvolvimento: reflexões sobre a experiência da COPASAD - Conferência Pan-Americana de Saúde e Ambiente no Contexto do Desenvolvimento Sustentável. Ciência \& Saúde Coletiva, v.3, n.2, p.33-46, 1998

PRATS, Y.. Décentralisation et développement. Paris. Editions Cujas, 1973

RONDINELLI, D. A.. A Government descentralization in comparative perspective: theory and practice in developing countries. Review of Administrative Sciences, v.47, n.2, p.133-145, 1981.

SERENO, C.; SANTAMARÍA, M.; SERER, S. A. S.. El rururbano: espacio de contrastes, significados y pertenencia, ciudad de Bahía Blanca, Argentina. Cuadernos de Geografía: Revista Colombiana de Geografía, v.19, p.41-57, 2010.

SOUZA, G. L. R.; OLIVEIRA, T. M.. Reflexões sobre Meio Ambiente, Direitos Humanos e Demografia Ambiental. Revista Brasileira de Gestão e Engenharia, n.6, p.83-86, 2012.

TAMBELLINI, A. T.; CÂMARA, V. M.. A temática saúde e ambiente no processo de desenvolvimento do campo da saúde coletiva: aspectos históricos, conceituais e metodológicos. Ciência \& Saúde Coletiva, v.3, n.2, p.47-59, 1998.

ZULAUF, W. E.. O meio ambiente e o futuro. Estudos Avançados, v.14, n.39, p.86-99, 2000. 